\title{
Comparison of the Phase Changes of Binary Mixtures n-Alkanes of Lower Carbon Numbers
}

\author{
Mfon C. Utin ${ }^{1}$, Samuel E. Ofodile ${ }^{1}$,Leo C. Osuji ${ }^{1}$, Gloria I. Ndukwe ${ }^{2}$ and Victor \\ J. Aimikhe ${ }^{3}$ \\ ${ }^{1}$ Department of Pure and Industrial Chemistry, University of Port Harcourt, P.M.B. 5323 Choba, Rivers State, \\ Nigeria \\ ${ }^{2}$ Chemistry Department, Faculty of Science, Rivers State University of Science and Technology, Nkpolu- \\ Oroworukwo, P.M.B. 5080Port Harcourt, Rivers State, Nigeria \\ ${ }^{3}$ Department of Gas Engineering, University of Port Harcourt P.M.B. 5323 Choba, Rivers state, Nigeria
}

\begin{abstract}
Existence of hydrocarbons are in various phases such as vapour, liquid and solid. Phase behaviour focuses on the state of equilibrium. This research develops the different phase envelope of precipitation of heavy organics using single and binary mixture of various ratios. The phase envelopes for the single and binary mixtures of various ratios (0:1, 1:0, 1:1, 1:2, 2:1, 1:3 and 3:1) were developed using ASPEN HYSIS 8.4 software which gives the qualitative results of the various precipitation processes. The results obtained show larger envelope with higher volume ratio of the lower carbon number (C5:C7, C5:C6 and C6:C7) being 2:1 and 3:1. The different binary mixtures for the equal volume ratios (1:1) also show larger envelopes at which the maxima were observed. The solid-liquid phase envelopes yield envelopes similar to that of the vapour-liquid phase.
\end{abstract}

Keywords: Crude oil, distillation process, $n$-alkane solvents, binary mixture, carbon number range.

\section{Introduction}

Crude oil composes of paraffinic and aromatic hydrocarbon molecules consisting of variable amounts of sulfur, oxygen, nitrogen and trace amounts of metals such as nickel, vanadium, iron and copper $[13,15,21]$.Chemical composition of crude oils differs according to location and age of the field. Heavy crude oils contain higher complex hydrocarbon molecules, heteroatoms and metal contents compared with lighter crude oil [20]. Crude oil is needed in various field in the petroleum industry example are studies related to reservoir evaluation, processing, environmental effects and migration [12]. Differential techniques are used in fractionating crude oils [13].The saturate, aromatic, resin and asphaltene(SARA) technique is the most widely used method to separate crude oils into four major fractions based on differences in solubility and polarity $[7,11,18,12]$. The saturate fraction mostly contains aliphatic compounds; the aromatic fraction consists of aromatic groups with aliphatic side chains. Resin is a heavier fraction than aromatic and saturate. Asphaltene is insoluble in n-alkane solvents and the most complex fraction of crude oils. These circumstances of higher asphaltene content in crude oil cause processing problem during refining operation $[2,16,7]$

Reservoir hydrocarbons exist as vapour, liquid or solid phase. A phase is defined as a part of a system which is physically distinct from other parts by definite boundaries. A phase is fully defined when its composition, temperature and pressure is specified. Phase behavior focuses only on the state of equilibrium. A system reaches equilibrium when it attains its minimum energy level. At equilibrium a system may form a number of co-existing phases with all the fluid constituents present in all the equilibrated phases [3].

Solid can be precipitated when the oil undergoes phase transition due to changes in pressure, temperature and composition. Precipitation can lead to solid particle build up and deposition. The presence of precipitated solid in the oil can also change the flow rate, flow properties and type of solid precipitated. Precipitation is the first step leading to solid build up and deposition and can also be found in the reservoir, transportation pipeline and well bore [1,9]

It has been reported that live oils yield significantly higher amounts of precipitates than dead oils from similar point, obtained at the same time and that multiple-contact experiments gave rise to more precipitation than single contact experiment. Field asphaltene precipitate resulting from a rich-gas or $\mathrm{CO}_{2}$ injection process are different from laboratory asphaltene induced by the addition of alkane. This field asphaltene is also different from the field asphaltene resulting from pressure depletion, and its nature also varies with the composition of the injection fluid [19].

The complexity of the phase behavior in petroleum fluids is due to the existence of the variety and polydispersity of hydrocarbon and other organic molecules in them [8].The phase behavior of a typical pure fluid can be represented on a pressure-temperature diagram. According to Gibb's phase rule, there is no degree 
of freedom when three phases must be in equilibrium which implies that three phases must be in equilibrium only at one temperature and pressure and is called triple point. The temperature and pressure of the triple point are determined. For two phase system, the degree of freedom is one and either temperature or pressure but both cannot be set. Once the temperature is specified, the pressure is determined. Thus, two equilibrium phases are represented by curves on a pressure-temperature diagram. The critical point occurs when the temperature and pressure along the vapourization curve is increased to the critical pressure and temperature.For single component systems, one single curve represents all the three conditions(vapour pressure, dewpoint and bubble point), simply because vapour pressure equal dewpoint equal bubble point. Once saturation temperature and pressure have been selected, there is one saturation temperature associated with it. This is only true for a single component system since it is the only temperature (at the given pressure) at which liquid and gas phase will coexist in equilibrium and is governed by Gibb's phase rule. Bubble point is the temperature(at a given pressure) where the first bubble of vapor is formed when heating a liquid consisting of two or more components while dew point temperature is the temperature at which air must be cooled at constant pressure [3].

The behavior of a hydrocarbon mixture at reservoir and surface conditions is determined by its chemical composition and the prevailing temperature and pressure. This behavior is of a prime consideration in the development and management of reservoirs, affecting all aspects of petroleum exploration and production. Although a reservoir fluid may be composed of thousands of compounds, the phase behavior fundamentals can be explained by examining the behaviour of pure and simple multicomponent mixtures. The behaviour of all real reservoir fluids basically follows the same principle, but to facilitate the application of technology in the industry, reservoir fluids have been classified into various groups such as the dry gas, wet gas, gas condensate, volatile oil and black oil [3].

The phase behaviour of a multicomponent system is more elaborate than that of a pure compound. The phase behaviour of a binary system, although relatively simple is very much similar to a multi-component reservoir fluid. It is an appropriate substitute for examining the qualitative behaviour of reservoir hydrocarbons mixture. The phase rule indicates that in a binary vapour-liquid system, both the temperature and the pressure are independent variables. The phase envelope, inside which the two phases coexist, is bounced by the bubble point and dew point curves. The two curves meet at the critical point, where all differences between the two phases vanish and the phases become indistinguishable. The two phases can coexist at some condition above the critical point. The highest pressure and the highest temperature on the phase envelopes are called thecricondenbar and the cricondentherm respectively [3].

Temperature corresponding to the atmospheric pressure is known as the normal boiling point or boiling point of the compound. Boiling increases from hexane to cyclohexane, benzene to pyridine and to aromatic amine. High boiling doesn't show heavy molecules but big aromaticity relative to the other species in crude oil [5,3]. It has been reported that three transition (phases) stages was observed using both single and binary mixture of $\mathrm{n}$-alkanes which shows a decrease in quantity of the precipitate as the carbon number of $\mathrm{n}$ alkanes solvents increases [8] but failed to mention that phase envelope can be used in their relationship. In this research, the aim is to relate the different binary mixtures using lower $n$-alkane solvent by its weight basis with the behaviour of the phase envelope application.

\section{Materials and Method}

The apparatus used for this research are filtration system, hot plate, distillation system, thermometer,desiccators and membrane filter.Pentane, $\mathrm{n}$-Hexane and Heptane were solvents used.Boma crude oil used for this research was obtained from Nigerian National Petroleum Corporation Research and Development Centre, Port Harcourt, Nigeria.

The reduced crude oil residue was obtained by removing the distillates at $260^{\circ} \mathrm{C}$ using atmospheric distillation at constant pressure and flow rate of $14.7 \mathrm{psi}$ and $20 \mathrm{~g} / \mathrm{hr}$ respectively. Precipitation of heavy organics was carried out using both the single solvent and binary mixture of the lower $\mathrm{n}$-alkane solvents.Thirty milliliters $(30 \mathrm{ml})$ of each of the solvent (pentane, hexane and heptane) and 30ml of each binary mixture (C5:C6, C5:C7 and $\mathrm{C} 6: \mathrm{C} 7$ ) were added to $1 \mathrm{~g}$ of the reduced oil in their appropriate flask. The mixtures were shaken for 30mins using mechanical shaker and kept for $48 \mathrm{hrs}$ before filtration. To separate the solid precipitate and the filtrate,each of the solution was filtered using the vacuum pump system with $0.45 \mathrm{~mm}$ membrane filter fitted in a Buchner funnel and flask connected to a vacuum pump. The solid precipitate was dried in an oven, weighed and kept in a desiccator. The phase envelopes for the various binary mixtures were modeled using the Soare Redlich Kwong (SPK) equation of state fluid package of ASPEN HYSIS 8.4 software. 


\section{Result and Discussion}

The phase envelopes of the different binary mixtures of their various ratios are shown below:

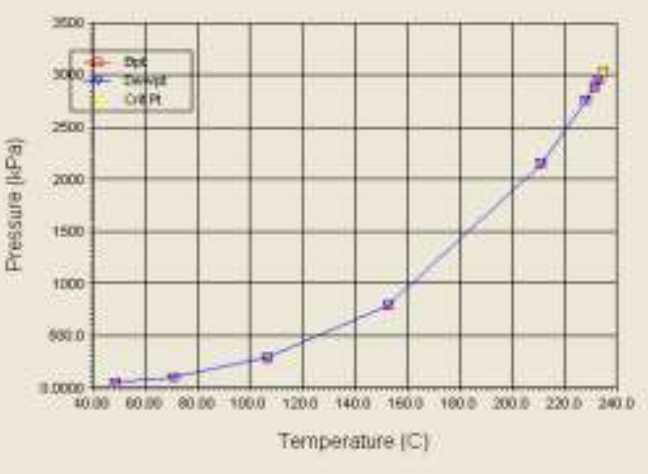

Fig 1: Phase envelop of single C6

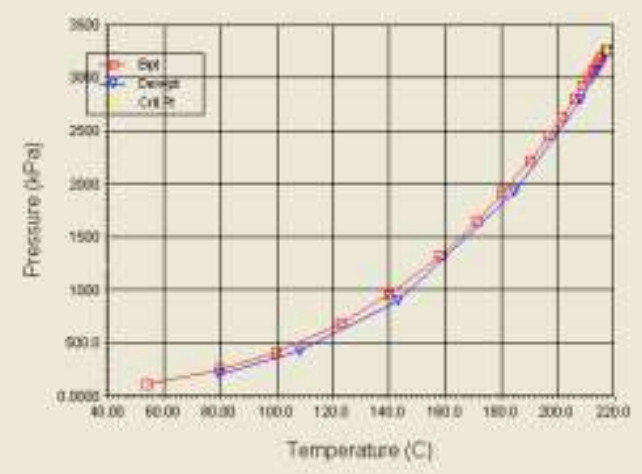

Fig 3: Phase envelop of C5:C6 (1:1)

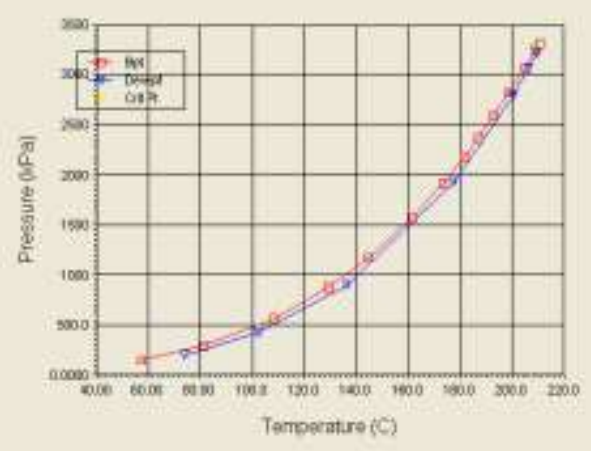

Fig 5: Phase envelop of C5:C6 (2:1)

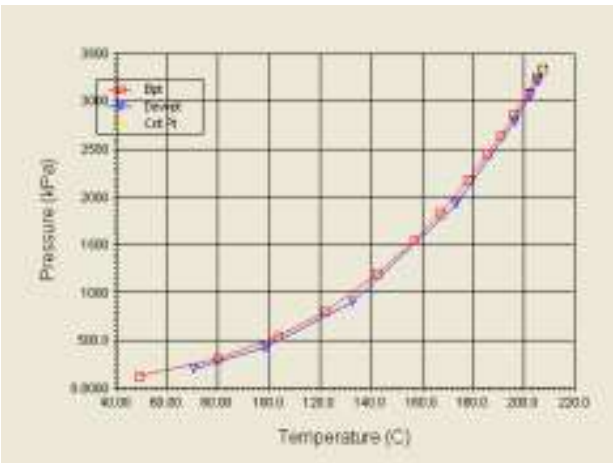

Fig 7: Phase envelop of C5:C6 (3:1)

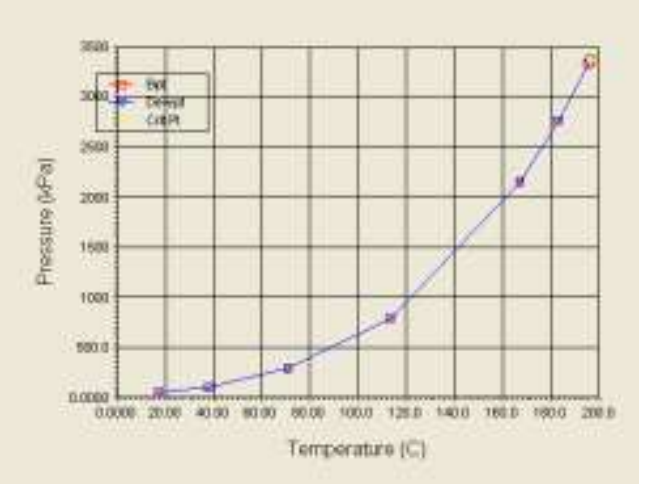

Fig 2: Phase envelop of C5

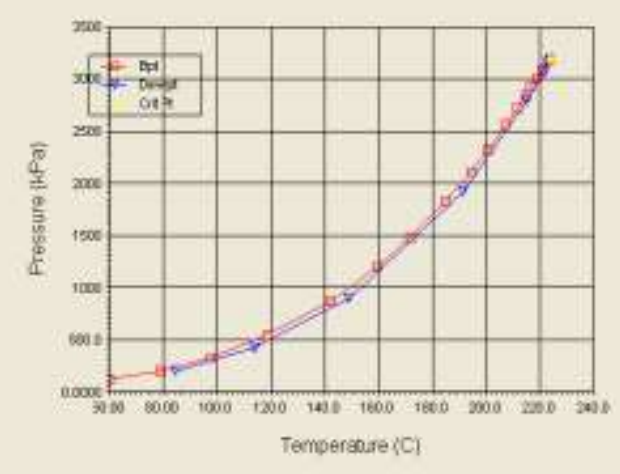

Fig 4: Phase envelop of C5:C6 (1:2)

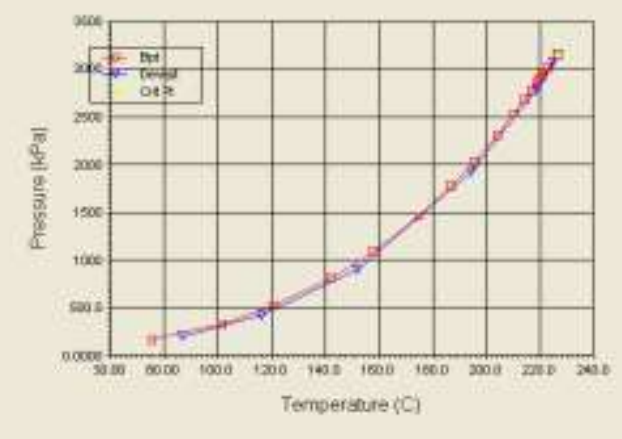

Fig 6: Phase envelop of C5:C6 (1:3)

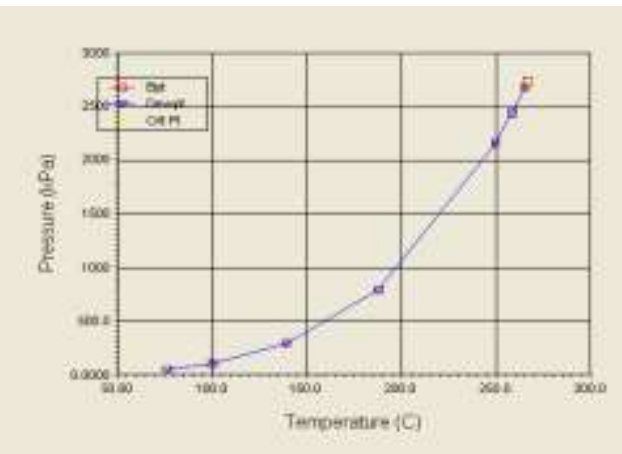

Fig 8: Phase envelop of C7 


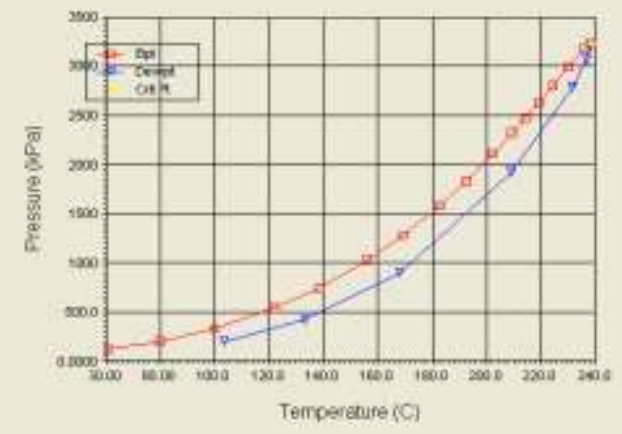

Fig 9: Phase envelop of C5:C7 (1:1)

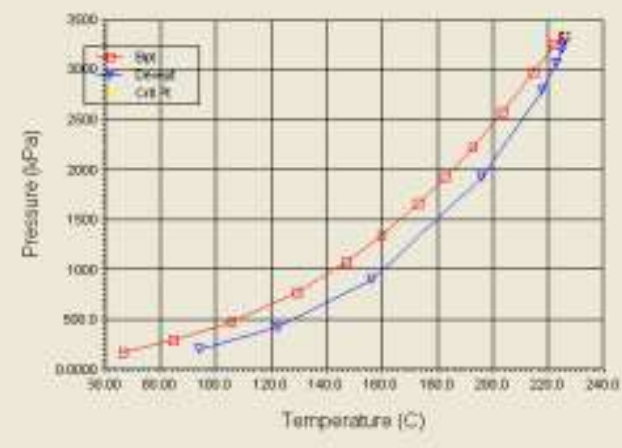

Fig 11: Phase Envelop of C5\&C7 (2:1)

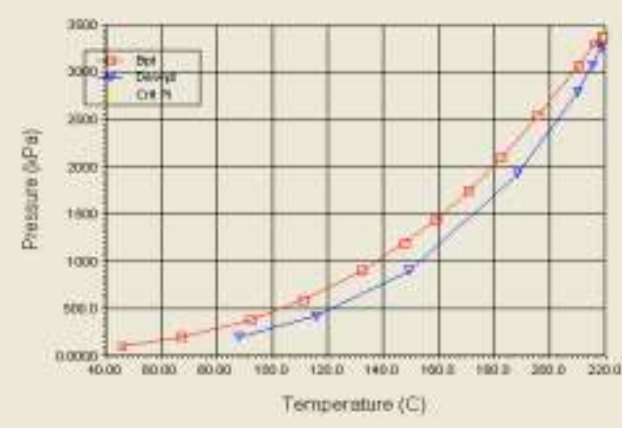

Fig 13: Phase Envelop of C5\&C7 (3:1)

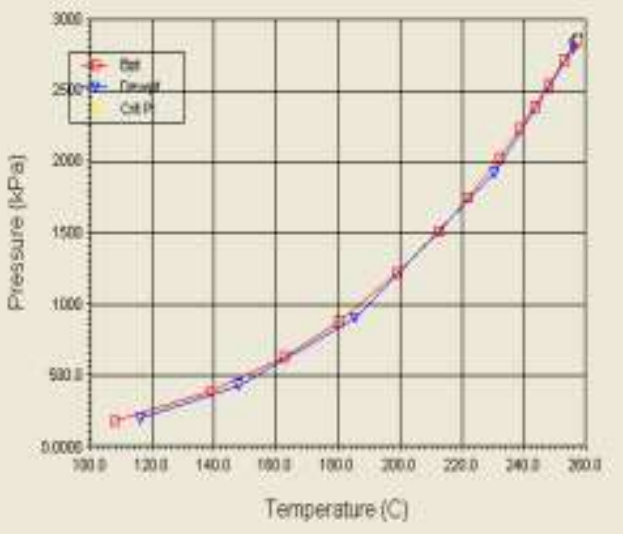

Fig 15: Phase envelop of C6:C7 (1:2)

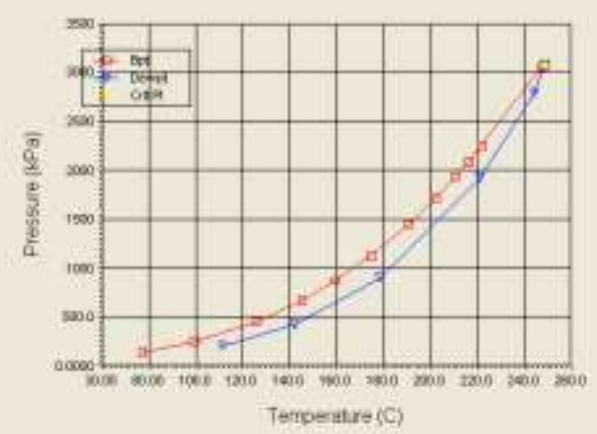

Fig 10: Phase Envelop of C5:C7 (1:2)

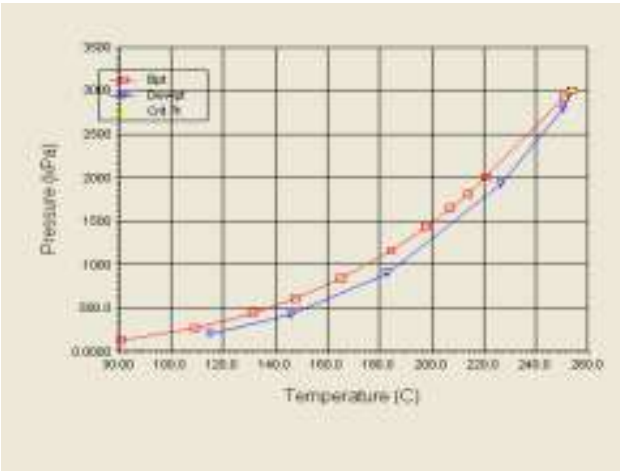

Fig 12: Phase Envelop of C5:C7 (1:3)

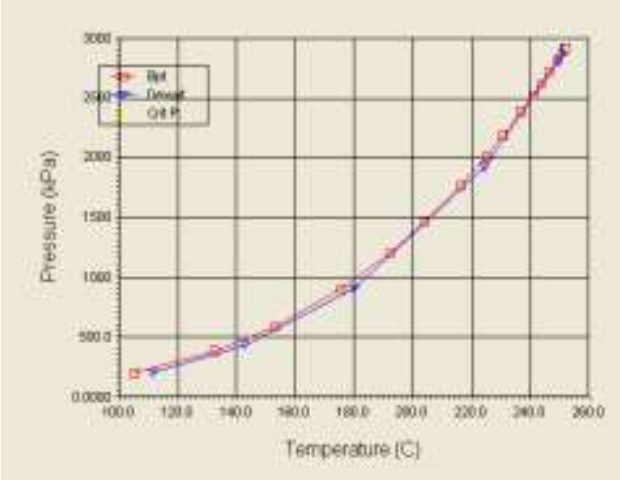

Fig 14: Phase envelop of C6:C7 (1:1)

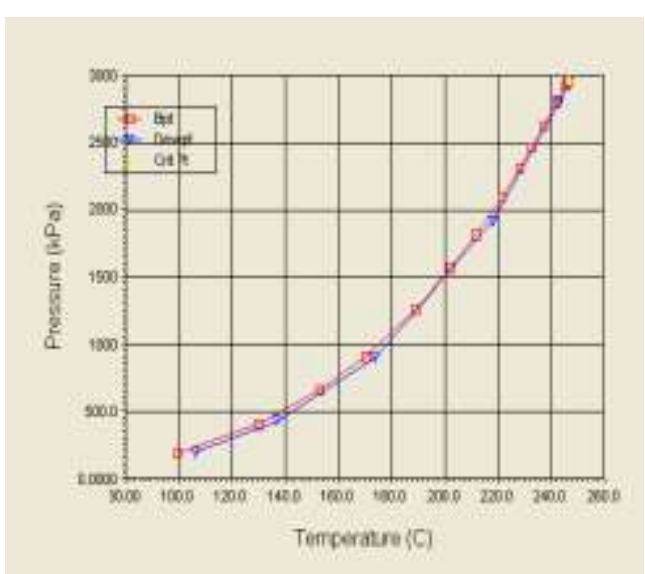

Fig 16: Phase envelop of C6:C7 (2:1) 


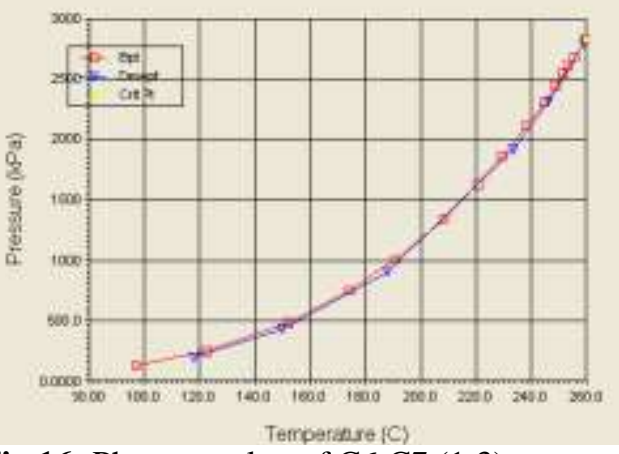

Fig 16: Phase envelop of C6:C7 (1:3)

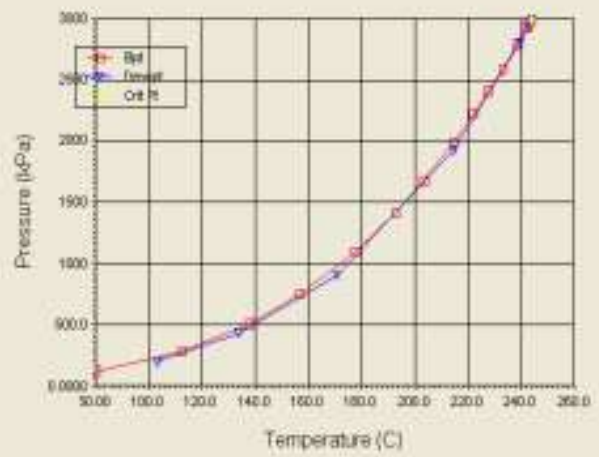

Fig 17: Phase envelop of C6:C7 (3:1)

The single carbon precipitants show single curves as seen in figures 1,2 and 8 which is in line with reported work[3]. The binary mixture precipitants in figures 3-7 and figures 14-18 show that the closer the carbon numbers used for the binary mixtures, the smaller the phase envelope and vice versa and this was clearly seen when compared with each respective ratio in figures 3-7 to figures 9-13 and figures 14-18 to figures 9-13. It was equally observed that the phase envelope with the highest volume of the lower carbon number shows a larger envelope which was clearly seen in figure 11 and figure 13 compared to figure 10 and figure 12 . The phase envelope of figure 13 and figure 11 were larger because of the highest volume of pentane used in the mixtures which is in line with the view by previous researchers that the amount of asphaltene increases as the carbon number decreases [22,1]. In comparing the phase envelopes in figures 3-7 to the phase envelopes of figures 14-18, it was observed that the phase envelope with more of the lower carbon numbers shown in figures 3-7 recorded larger envelopes compared to the phase envelopes of figures 14-18 with higher carbon number. According to [8], for a given volume of precipitant, the amount of the heavy organic precipitate decreases as the carbon number of $\mathrm{n}$-alkane precipitants increases. According to [22], the molecular weight distribution of $\mathrm{nC}_{5}, \mathrm{nC}_{7}$ and $\mathrm{nC}_{9}$ are different since solubility properties of the precipitated asphaltenes vary according to the solvent used for their precipitation. The resin content in the precipitates increases as the number of carbons in the precipitating solvent decreases. The study with $\mathrm{nC}_{5}, \mathrm{nC}_{6}$ and $\mathrm{nC}_{7}$ records a general trend similar to those observed by other researchers in their experiments [4,10,22]. For binary mixture of n-alkanes reported in this work, lower carbon number n-alkane binary mixtures also recorded bigger phase envelope while higher carbon number binary mixtures recorded smaller phase envelope. However, [8] reported the trends of precipitation as the volume of corresponding precipitant mixture altered differs completely from those of single n-alkane precipitants. The phase envelope of 1:1 precipitants of their various binary mixtures show significant difference compared to others and this was clearly observed in figure 9 since the carbon numbers are not so close. These explain the reported work by [8], that precipitation with binary mixture n-alkane show three stage transitions solid-liquid, liquid-solid and solid-liquid as the volume ratios of precipitants vary. The maxima were clearly seen in the 1:1 binary mixture which the phase envelope of 1:1 is significantly different from others that were observed at the minima.

\section{Conclusion}

The phase envelope gives a qualitative evidence of the asphaltene and resin contents reported by previous researchers on their weight basis(quantitative analysis) which is similar to what is happening at their different ratios of both single and binary mixture combination. It shows that the compositional differential analysis of $\mathrm{nC}_{5}: \mathrm{nC}_{7}$ will be quite large and different compared to $\mathrm{nC}_{5}: \mathrm{nC}_{6}$ and $\mathrm{nC}_{6}: \mathrm{nC}_{7}$ depending on their method of precipitation. It equally gives an ideal why the maxima were observed at 1:1 ratios of the different binary mixtures.

\section{References}

[1] A.K Tharanivasan, Asphaltene Precipitation from Crude Oil Blends, Conventional Oils and Oils with Emulsified Water, 2012.

[2] Ali, M. F. Bukhari, A, \&U. M Hasan. Structural Characterization of Arabian Heavy Oil Residue. Fuel Sen Tech Int. 1989

[3] Ali Danseh. PVT \& Phase Behavior of Petroleum Reservoir Fluids Publisher: Elsevier sciences \& Technology Broks 1998.

[4] B.G Edward,L.G Calos, G.V Alejandro G.V \& W. Jianzhong. Asphaltene Precipitate in Crude Oils. Theory and Experiments. Al CHE Journal 2004.

[5] C.H Arnaud. Digging into Asphaltenes Volume 87 Issue 38/pp. 12-17, Chemical \& Engineering News CASC \& ENACS Publications, 2009.

[6] E. Gonzalez, C. Galeana,A. Villegas and W. Jianzhong. Asphaltene Precipitation in Crude Oils: Theory and Experiments, 2004, 50(10) 2552-2570.

[7] Fan Tianguang \& Buckley Jill, J. S. Rapid \& Accurate SARA Analysis of Medium Gravity Crude Oils. Energy Fuel 2002, 16:15711575 . 
[8] G.Udourioh, M. Ibezim-Ezeani and S. Ofodile . Comparative Investigation of Heavy Organics Precipitation from Crude Oil Using Binary Mixtures and Single N-alkane Organic Solvents. Journal of Petroleum and Gas Exploration Research, 2014, 4(4) 53-59

[9] G Ali Mansoori. Phase Behavior in Petroleum Fluids: A Detailed Description \& Illustration Account with emphasis on Heavy Organics, 2008

[10] G. Udourioh,M. Ibezim-Ezeani,U. Millicent, U and S. Ofodile. The Effect of Compositional Changes of Binary Mixtures of NAlkane Solvents on the Precipitation of Heavy Organics from a Solution of Crude Oil Residue (2015).

[11] G.A Klein, A. Anaystrom, R.P Rodgers\&A.G Marshall. Use Of Saturate/Aromatic/Resins/Asphaltenes (Sara) Fracturation To Determine Matrix Effects In Crude Oil Analysis By Electrospray Ionization Fouvier Transform Ion Cydotrion Resonance Mass Spectrometry. Energy fund,2006.

[12] I. Mohammed .and L. Okoro. A Review on the Effect of Asphaltene Petroleum Processing. Eur.chem Bull, 2013,2(6), 393-396.

[13] J.G Speight. Handbook of Petroleum Analysis, New York: John Wiley \& Sons ,2001.

[14] L. Goual. Petroleum Asphaltene. University of Wyoming USA (www.intechnopen.com), 2012.

[15] M. Yasar, D. M. Tranth, M.T Klevin. Asphaltene \& resin pyrolysis:2, Effect of Reaction Environment on Pathways \& Selectivity. Energy fuel (2001)

[16] M.R Gray. Upgrading Petroleum Residues \& Heavy Oils New York: Marcel Dekker ,1994.

[17] Narve Aske .Characterisation of crude Oilcomponents, Asphaltene Aggregationand Emulsion Stability By Means Of Near Infrared Spectroscopy and Multivariate Analysis.Department of Chemical Engineering, Norwegian University of Science and Technology (2002).

[18] Peralta-Marling, M.V Vazguez-Ramirez, R. G. Blass Armador\&E.M Palacios-Lozano. Determination of Functional Groups in Mexican Vacumm, Residua, Petrol.Scietech (2008).

[19] Petrowiki. Asphaltene precipitation, petrowiki.org/Asphaltene precipitation., 2015.

[20] S. Akmaz, O. Iscan, M.A Gurkaynak. \& M. Yasa. The Structural Characterization of Saturate Aromatic, Resin \& Asphaltene Fractions of Batiraman Crude Oil, 2011.

[21] V. Simanzhenkor\& R. idem. Crude Oil Chemistry New York: Marcel Dekkar ,2003.

[22] D. Vazquez, and G.A. Mansoori, Identification and Measurement of Petroleum Precipitates. Journal of Petroleum Science and Engineering. (2000) 26, 49-55. 